\title{
Characterization of Mouse Switch Variant Antibodies by Matrix-Assisted Laser Desorption Ionization Mass Spectrometry and Electrospray Ionization Mass Spectrometry
}

\author{
Satoko Akashi, ${ }^{*}$ Kazuyoshi Noguchi, Reiko Yuji, Uno Tagami, and \\ Kazuo Hirayama \\ Central Research Laboratories, Ajinomoto Co., Inc., 1-1 Suzuki-cho, Kawasaki-ku, Kawasaki 210, Japan \\ Koichi Kato, HaHyung Kim, ${ }^{\dagger}$ Kazuhiro Tokioka, Ichio Shimada, and \\ Yoji Arata $^{\ddagger}$ \\ Faculty of Pharmaceutical Sciences, University of Tokyo, Hongo, Tokyo 113, Japan
}

\begin{abstract}
The amino acid sequences of mouse monoclonal antibodies have been characterized completely by mass spectrometry. Antibodies used in the present study were derived from mouse switch variant cell lines that produce four kinds of immunoglobulin Gs (IgGs). The amino acid sequences of these antibodies had not been estimated from the corresponding DNA sequence, so the sequences of IgGs derived from other strains were used as references in this study. Intra- and interchain disulfide bonds of the IgGs were reduced and carboxymethylated and the products were subjected to proteolytic digestion. The existence of $\mathrm{N}$-linked oligosaccharides also was taken into account. The capabilities and limitations of matrix-assisted laser desorption ionization-time-of-flight mass spectrometry and capillary liquid chromatography-electrospray ionization mass spectrometry are discussed in the structural characterization of the antibodies. Based on our results, allotypes of the antibodies examined are discussed. This study shows that amino acid sequences of proteins, such as IgG, can be investigated without information about the corresponding DNA sequence if appropriate reference sequences derived from other strains can be used. (J Am Soc Mass Spectrom 1996, 7, 707-721
\end{abstract}

$\mathrm{E}$ lectrospray ionization (ESI) and matrix-assisted laser desorption ionization (MALDI) methods have expanded greatly the analytical applicability of mass spectrometry to the structure investigation of biological macromolecules. Not only the determination of the molecular weight, but also the characterization of peptides derived from enzymatic digestion of the proteins, can be achieved by ESI and MALDItime-of-flight (TOF) mass spectrometry. A great advantage of ESI and MALDI/TOF mass spectrometry is that only a small amount of sample is required to determine the molecular weight and the sequence characterization of proteins. This is especially true in

Address reprint requests to Dr. Kazuo Hirayama, Central Research Laboratories, Ajinomoto Co., Inc., 1-1 Suzuki-cho, Kawasaki-ku, Kawasaki, Kanagawa 210, Japan.

* Present address: Division of Biomolecular Characterization, The Institute of Physical and Chemical Research (RIKEN), 2-1 Hirosawa, Wako, Saitama 351-01, Japan.

'Present address: College of Pharmacy, Chung-Ang University, Huksuk-dong 221, Dongjak-ku, Seoul 156-756, Korea.

${ }^{\ddagger}$ Present address: Water Research Institute, Sengen 2-1-6, Tsukuba, Ibaraki 305, Japan. the case of MALDI, which requires the sample to be only in the subpicomole to femtomole range. In addition, a large number of peptides can be observed in a single MALDI/TOF mass spectrum of digested peptides $[1,2]$. Advances in these techniques have made it possible to deal easily with biological macromolecules by mass spectrometry.

Immunoglobulin $G(\operatorname{IgG})$, which has a molecular mass of $150 \mathrm{ku}$, and its fragments have been analyzed by electrospray ionization mass spectrometry (ESI-MS) [3-6] and matrix-assisted laser desorption ionizationtime-of-flight/ mass spectrometry (MALDI/TOF-MS) [7]. Peptide mapping also has been performed for the characterization of a recombinant humanized monoclonal antibody by ESI-MS [8] or MALDI/TOF-MS, liquid secondary ionization mass spectrometry (LSIMS), and ESI-MS [9]. In these studies, it was impossible to detect all of the molecular masses of digested peptides by LC/ESI-MS or MALDI/TOF-MS measurement. Recently, Roberts et al. [10] reported complete structural characterization of a recombinant, reshaped human monoclonal antibody by mass spectrometry. 
These studies were performed for the structure verification of recombinant products that included the structure of the $\mathrm{N}$-linked sugar chain. In the present work we have used mass spectrometry successfully to characterize the amino acid sequences of IgGs whose amino acid sequences had not been estimated from the corresponding DNA sequence.

IgG consists of two identical heavy chains and two identical light chains. The heavy chains are composed of four homologous units, $V_{H}$ (variable region of the heavy chain), $C_{H} 1, C_{H} 2$, and $C_{11} 3$ (constant regions of the heavy chain), whereas the light chains are divided into two homologous units, $V_{L}$ (variable region of the light chain) and $C_{L}$ (constant region of the light chain). The $\mathrm{C}_{\mathrm{H}} 2$ domain has an Asn-linked oligosaccharide. The amino acid sequences of the variable region that recognizes the antigen always have been analyzed carefully. By contrast, little has been done on the amino acid sequences of the constant region of IgG, because the amino acid sequences of the constant region are believed to be highly homologous. The existence of allotypic markers in the heavy chain long has been known and the immunological significance of allotype is well documented [11]. Allotypic markers with specific amino acid substitutions traditionally have been characterized by using antiallotypic sera. However, specific antiallotypic sera are not always obtainable. More importantly, allotypic markers that happen to correspond to amino acid residues are not always located on the surface of the protein molecules and would not be detected by the conventional antisera, because the sera would not be able to interact and detect the specific amino acid residues.

The IgGs used in the present mass spectrometric analyses belong to a switch variant family and have a number of interesting features. A switch variant family that produces mouse antidansyl monoclonal antibodies has been generated by Dangl et al. [12]. This family of mouse switch variant antibodies produced by $\mathrm{C} 3 \mathrm{H} / \mathrm{SW}$ strain cells recognizes the identical antigen-dansyllysine-and contains four subclasses. Hereafter, these antidansyl antibodies will simply be referred to as the four subclasses IgG1, IgG2a, IgG2b, and IgG2a(s). IgG2a(s) is an interesting short-chain IgG2a variant, in which the entire $C_{H} 1$ domain is deleted from the normal IgG2a [13]. A fascinating feature of these antibodies is that they possess the identical $V_{H}, V_{L}$, and $C_{L}$ in conjunction with different heavy chain constant regions, according to the definition of switch variant. However, little attempt has been made to identify the amino acid sequences of $V_{H}, V_{L}$, and $C_{L}$ regions of these antibodies or to determine the sequences of the constant regions of the heavy chain because of the large molecular weights of the antibodies. This set of switch variant antibodies provides an interesting opportunity to apply mass spectrometry to a number of problems of immunochemical interest; it is significant just to characterize the structure of all these antibodies, which include the $\mathrm{N}$-linked sugar chain. DNA sequence information for the constant region of the heavy chain was not obtained for each switch variant antibody. Therefore, amino acid sequences of other IgGs that belong to the same subclass but are derived from different mouse strains are used as references in this study. We selected several sequences of IgGs that originated from another close strain for reference sequences.

Establishment of the amino acid sequences of these switch variant antibodies is expected to enable us to characterize the structure of the allotypic marker(s) that exist in the heavy chain. Detection of amino acid substitution(s) compared to the reference sequences of other IgGs that belong to the other allotype would lead to the allotypic marker(s). Mouse IgG2a produced by $\mathrm{C} 3 \mathrm{H} / \mathrm{SW}$ strain, which belongs to haplotype-j strain, was classified as allotype-a, but it is now classified as allotype- $j$, because of its negative response to a conventional antiserum [14]. Only two kinds of guinea pig antisera can differentiate allotype- $j$ and allotype-a of IgG2a, and IgG2a investigated in this study has been classified into allotype-j by the serological criteria. Mouse IgGs of other subclasses produced by haplotype-j strain can be grouped into allotype-j, too, but no difference from allotype-a has been detected by any antiserum. Therefore, the amino acid sequences of IgGs that originate from haplotype-a strain and haplotype-j strain, that is, of IgGs that carry allotype-a and allotype-j, are expected to be quite similar. However, analyses of the amino acid sequences have not been carried out.

In this article we report the results of mass spectrometric characterization of the structure of mouse switch variant antibodies. Identification of the variable regions and characterization of the constant regions was achieved as was posttranslational modification. On the basis of the results obtained, the allotype of the switch variant antibodies is discussed. Another purpose of the present study is to discuss the characteristics of several mass spectrometric techniques for the identification of the structure of biological macromolecules with a molecular weight on the order of $150 \mathrm{ku}$. The capabilities and limitations of MALDI/TOF-MS and capillary LC/ESI-MS for peptide mapping of IgGs are compared.

The strategy we used is as follows. First, the molecular weights of IgG1, IgG2a, IgG2b, and IgG2a(s) were determined by MALDI/TOF-MS. MALDI/TOF-MS peptide mapping then was carried out. The amino acid sequences of IgGs produced by other mouse strains, which included haplotype-a, were used as references. Capillary LC/ESI-MS also was applied to complete the assignment of the observed mass values to the peptides obtained by the enzymatic digestion. All peptides with unexpected molecular weights were isolated by high-performance liquid chromatography (HPLC) and subjected to amino acid sequence analyses. Thus, a 
structural characterization of the mouse switch variant antibodies was accomplished. Immunochemical implications of the results obtained in this study in terms of the allotype of IgGs used are discussed.

\section{Experimental}

Materials. Dithiothreitol, iodoacetic acid, lysyl-endopeptidase, and trifluoroacetic acid (TFA) were purchased from Wako Pure Chemical Industries (Osaka, Japan). Staphylococcus aureus V8 protease was purchased from ICN ImmunoBiologicals (Costa Mesa, CA), chymotrypsin was purchased from Sigma (St. Louis, MO), and acetonitrile was purchased from Nacalai Tesque (Kyoto, Japan).

Preparation and purification of IgGs. The antidansyl switch variants IgG1, IgG2a, IgG2b, and IgG2a(s) that originate from $\mathrm{C} 3 \mathrm{H} / \mathrm{SW}$ mice (haplotype-j) were produced by cultivation of hybridoma cells and purification in the same manner as reported previously [15].

Reduction and S-carboxymethylation. Lyophilized IgG (550 $\mu \mathrm{g}$ ) was dissolved in $500 \mu \mathrm{L}$ of $0.5-\mathrm{M}$ Tris $-\mathrm{HCl}$ buffer ( $\mathrm{pH}$ 8.1) that contained 6-M guanidine and 2-mM ethylenediaminetetraacetic acid (EDTA). After addition of $900 \mu \mathrm{g}$ of dithiothreitol, the mixture was bubbled with nitrogen, heated at $50^{\circ} \mathrm{C}$ for $3 \mathrm{~h}$, and allowed to stand overnight at room temperature. To this solution $2.2 \mathrm{mg}$ of iodoacetic acid was added; the $\mathrm{pH}$ of the solution was kept at $8.0-8.5$ by using $0.1-\mathrm{N}$ $\mathrm{NaOH}$. After $30 \mathrm{~min}$, the protein was dialyzed against $50-\mathrm{mM}$ ammonium bicarbonate buffer at $4^{\circ} \mathrm{C}$, and lyophilized.

Proteolytic digestion of IgGs. Lysyl-endopeptidase digestion of reduced and carboxymethylated (RCM) IgG was performed under the conditions of a 200:1 molar ratio of substrate to enzyme in $50-\mathrm{mM}$ ammonium bicarbonate buffer ( $\mathrm{pH} 8.4$ ) at $37^{\circ} \mathrm{C}$ for $18 \mathrm{~h}$. V8 protease digestion of RCM-IgG was performed under the conditions of a 100:1 molar ratio of substrate to enzyme in $50-\mathrm{mM}$ ammonium bicarbonate buffer $(\mathrm{pH}$ 7.9) at $37^{\circ} \mathrm{C}$ for $15 \mathrm{~h}$. Chymotryptic digestion of a fractionated peptide was performed under the conditions of a 50:1 molar ratio of substrate to enzyme in $50-\mathrm{mM}$ ammonium bicarbonate buffer $\left(\mathrm{pH} \mathrm{7.9)}\right.$ at $37^{\circ} \mathrm{C}$ for $4 \mathrm{~h}$. The hydrolysis was stopped by addition of $5 \%$ acetic acid and then the solution was lyophilized.

Reversed phase (RP) HPLC. A conventional HPLC system that consists of two Jasco (Tokyo, Japan) 880-PU pumps was used. A Jasco 870 UV detector was set at $210 \mathrm{~nm}$. Isolation of proteolytic peptides for fast-atom bombardment (FAB) mass spectrometry and amino acid sequence analyses was performed on a Vydac (Hesperia, CA) C18 column $(4.6 \times 250 \mathrm{~mm})$. The sol- vents consisted of (A) $0.1 \%$ aqueous TFA and (B) acetonitrile:water 9:1 with $0.095 \%$ TFA. A linear gradient elution of $100 \%$ (A)-35\% (A) was performed for the isolation of peptides.

Matrix-assisted laser desorption mass spectrometry. All MALDI spectra were obtained by using a ShimadzuKratos KOMPACT MALDI-III time-of-flight mass spectrometer (Manchester, UK), which had a 337-nm nitrogen laser. The analyzer was used in the linear or reflector mode, at an accelerating voltage of $20 \mathrm{kV}$. Samples were dissolved in $0.1 \%$ TFA, and $0.5 \mu \mathrm{L}$ of the sample solution was deposited on a stainless sample slide. After drying with air, $0.5 \mu \mathrm{L}$ of .matrix solution [2,5-dihydroxybenzoic acid (DHBA) or 3,5-dimethoxy-4-hydroxycinnamic acid (sinapinic acid)/2(4-hydroxyphenylazo)benzoic acid (HABA) (20/1), in 0.1\% TFA: $50 \%$ ethanol (EtOH)] was added to the sample spot. For low molecular weight peptides (MW $<4000$ ), DHBA was applied as the matrix. For high molecular weight peptides ( $M W>2000$ ), the sinapinic acid:HABA (20:1) mixture was applied as the matrix. The sample slide was air-dried prior to transfer into the source of the mass spectrometer. The MALDI mass spectra were calibrated externally by using calibrant proteins (bovine serum albumin, lysozyme, or bovine insulin). A more accurate mass assignment of proteolytic fragments was achieved by using an identified peptide fragment and a matrix peak as internal calibrants.

Liquid chromatography-electrospray ionization mass spectrometry. The capillary HPLC system consisted of an ABI 140B dual syringe solvent delivery system (Applied Biosystems, Inc., Foster City, CA). A Kontron (Milano, Italy) 433 capillary detector was set at $210 \mathrm{~nm}$. The solvents consisted of (A) $0.1 \%$ aqueous TFA and (B) acetonitrile:water 9:1 with $0.095 \%$ TFA. A linear gradient elution of $100 \%$ (A)-35\% (A) was performed for the isolation of peptides by a Vydac C18 capillary column packed by LC Packings (San Francisco, CA). The solvents were mixed and split by an Acurate unit (LC Packings) and the flow rate was reduced to 2.7 $\mu \mathrm{L} / \mathrm{min}$. Electrospray ionization mass spectrometry (ESI-MS) was performed on a Finnigan-MAT (San Jose, CA) TSQ700 equipped with an Analytica electrospray ion source (Analytica of Branford, Branford, CT). Proteolytic peptides ( $30 \mathrm{pmol}$ ) were injected into the capillary HPLC system and then introduced into the mass spectrometer.

Fast-atom bombardment mass spectrometry. Fast-atom bombardment mass spectra were obtained by the first mass spectrometer of a JEOL (Tokyo, Japan) HX/110/ HX110 tandem mass spectrometer. The sample was dissolved in 1-N $\mathrm{HCl}$ and deposited on a stainless sample target. After addition of glycerol:thioglycerol (1:1) matrix, the sample target was introduced into the 
mass spectrometer. All spectra were obtained at a resolution of 3000 or 2000 , which enabled the detection of each peak with unit mass resolution.

Edman sequence analysis. Edman sequence analysis was performed on a Shimadzu (Kyoto, Japan) PPSQ-10 sequencer.

Peptide assignment. Molecular weights of the peptides were attributed to the sequences of the reference IgGs by using MacBioSpec (PESciex, Ontario, Canada).

\section{Results and Discussion}

\section{Molecular Weight Determination by MALDI/ TOF-MS}

Molecular weights of IgG1, IgG2a, IgG2b, and IgG2a(s) were determined by MALDI/TOF-MS. Figure 1 shows MALDI/TOF mass spectra of the four mouse immunoglobulins. In the case of IgG1, IgG2a, and IgG2b, the light chains and the heavy chains are bound with disulfide bonds. By contrast, no covalent bond exists between the light chains and the heavy chains in IgG2a(s), in which the entire $C_{\mathrm{H}} 1$ domain is deleted [13]. The IgG1, IgG2a, and IgG2b antibodies gave molecular peaks at $m / z 150,188,151,347$, and 152,156, respectively, whereas two molecular peaks were observed at $m / z 24,285$ and 83,612 in the case of $\operatorname{IgG} 2 a(s)$. There are no expected sequences for these IgGs from the corresponding DNA sequences, but sequences of IgGs derived from another strain are used as references and "expected" mass values are calculated. The method of selection for reference sequences for these IgGs is described in the following text. The "expected" mass values are 149,964 (IgG1), 151,700 (IgG2a), 152,238 (IgG2b), 24,128 [light chain for IgG2a(s)], and 83,443 [heavy chain for $\operatorname{IgG2a}(\mathrm{s})$ ], with the assumption that the major component of the $\mathrm{N}$-linked oligosaccharides of these antibodies is type $F$ or $G$ with a molecular weight of 1625.5 (average molecular weight) [16]; see Figures 1 and 2 . The mass difference between observed and "expected" mass values is within $~ 350 u$ in MALDI/TOF-MS of every subclass.

Bovine serum albumin was used as a calibrant to obtain the MALDI/TOF mass spectra in Figure 1, although the molecular weight of IgG is much larger than that of bovine serum albumin. This discrepancy results in relatively low accuracy for the determination of the molecular weights of IgGs. It has been reported that heterogeneous sugar chains are linked to Asn297H of IgGs [16]. In addition, the existence of adduct ions of matrices to the molecular ion must be taken into account in MALDI/TOF-MS of proteins with large molecular weight. Accordingly, it is difficult to determine the molecular weight of IgGs exactly. A result of MALDI/TOF-MS analyses of intact molecules of the switch variants suggests that sugar chains are linked to
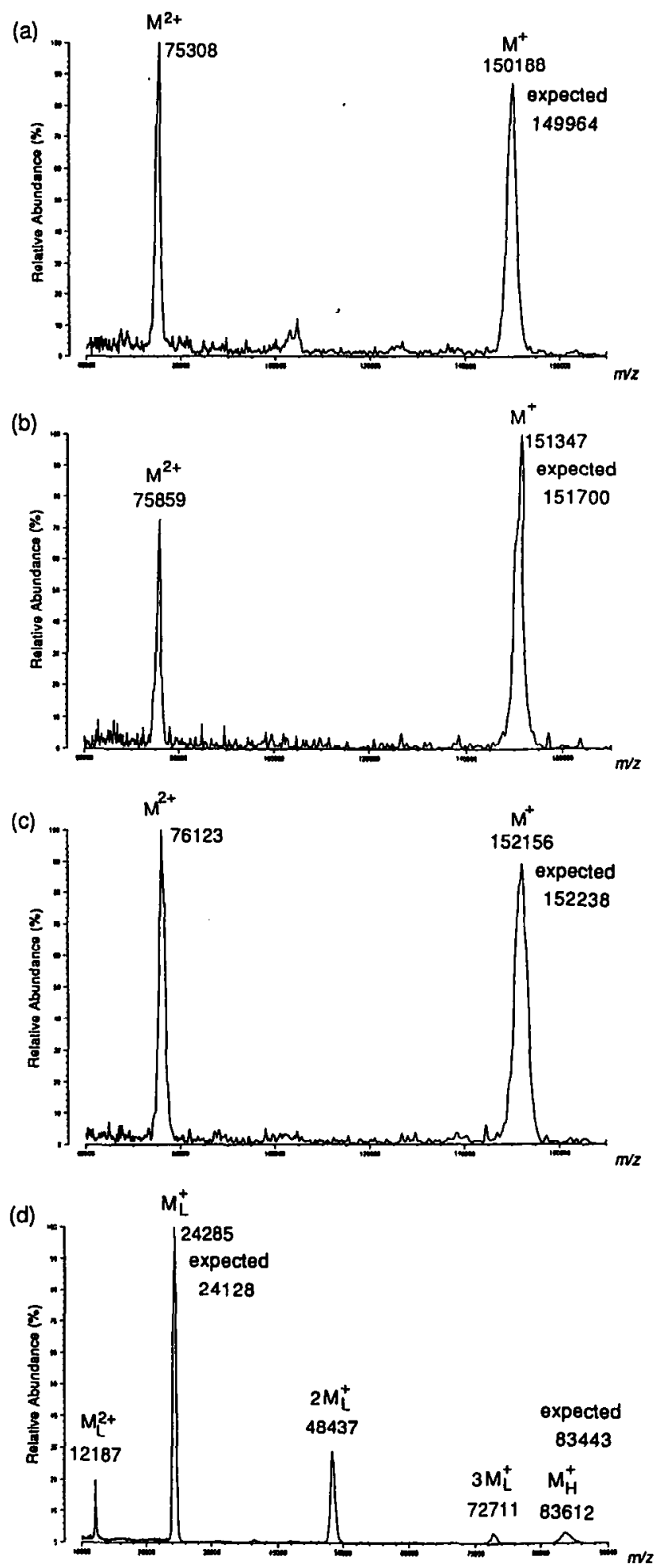

Figure 1. MALDI/TOF mass spectra of (a) IgG1, (b) IgG2a, (c) $\operatorname{Ig} G 2 b$, and (d) IgG2a(s).

IgG molecule, as expected, and their average molecular weights are $\sim 3 \mathrm{ku}$.

\section{Reference Sequences for the Study}

When peptide mappings of large proteins are carried out by mass spectrometry, information on amino acid 
(a)

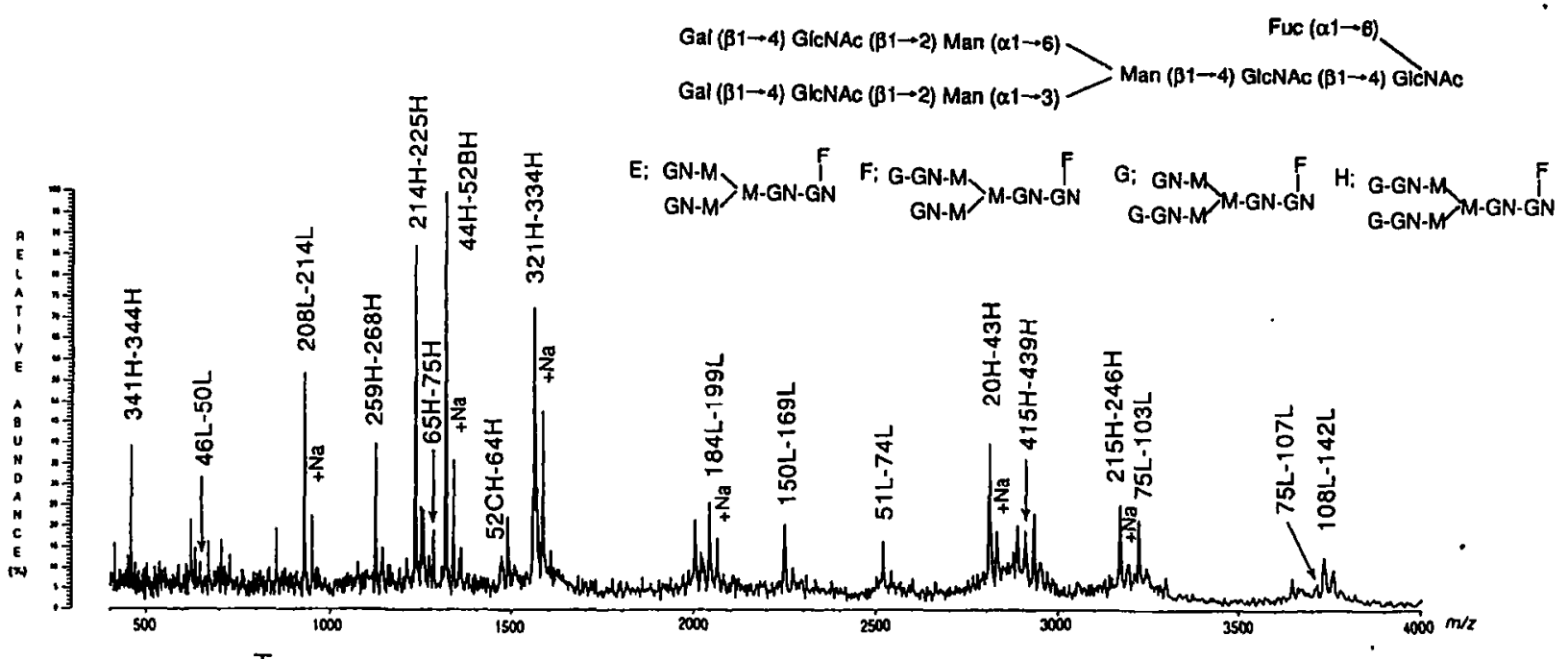

(b)

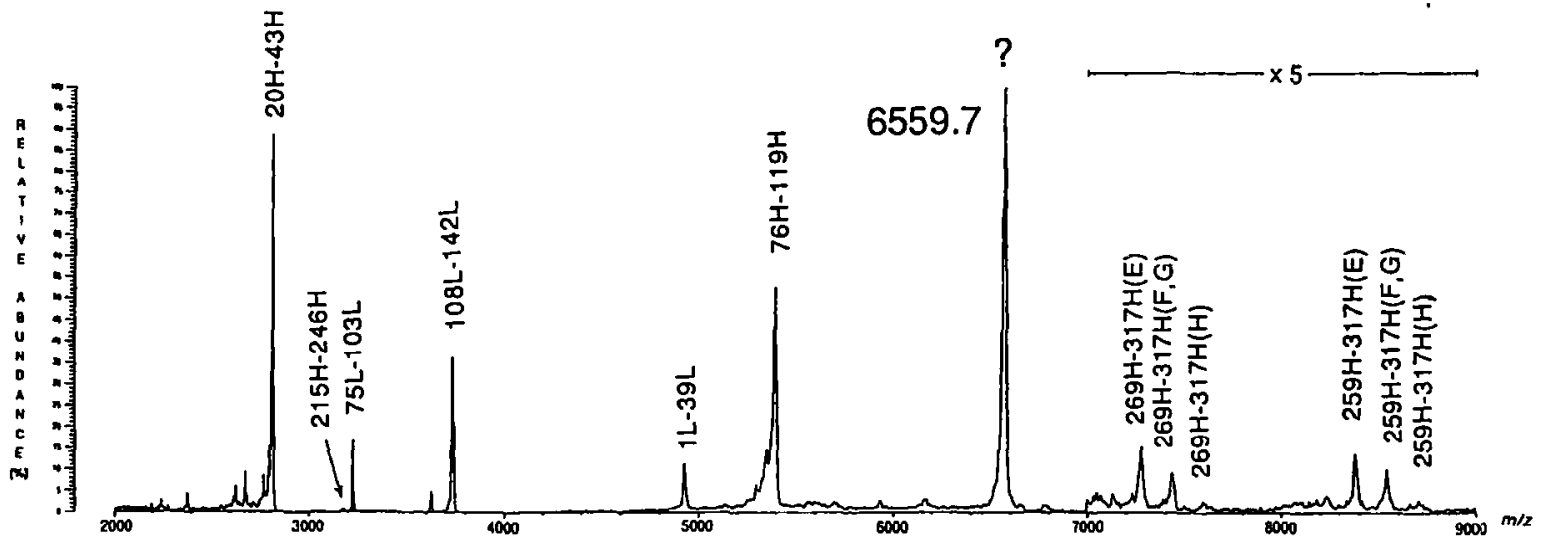

Figure 2. MALDI/TOF mass spectra of the lysyl-endopeptidase digest of RCM IgG1. (a) DHBA matrix; (b) sinapinic acid: HABA (20:1) matrix. Structures of oligosaccharides linked at Asn297H are indicated at the top of the figure. Symbols: G, galactose; M, mannose; F, fucose; GN, N-acetylglucosamine. The complete structure of $\mathrm{H}$ also is given.

sequences is necessary as a reference, because it is difficult to determine the unknown amino acid sequence by mass spectrometry only. Identical amino acid sequences for the $V_{L}$ and $V_{H}$ regions were used as references in the present study [17], because these IgGs belong to a switch variant family (The definition of switch variant is that they have the identical variable regions in their genetic sequences. The amino acid sequence of the $V_{H}$ region of the switch variant antibody IgG1 used in the present study was given by Dangl [17]. The sequence of the $V_{L}$ region of the switch variant IgG1 was kindly provided by Professor L. A. Herzenberg, Stanford University, and Dr. V. T. Oi, Becton Dickinson Immunocytometry Systems. Sequence data of the $C_{L}$ region were reported for mouse myeloma protein MOPC21 [18]. These sequence data were used as references for $V_{H}, V_{L}$, and $C_{L}$ regions in all switch variant antibodies in this study.) The identical sequence for the $C_{L}$ domain also was used as a reference for these IgGs, because of the belief that only one sequence exists that corresponds to the $C_{L}$ domain in the light chain classified into $\kappa$ subgroups in the case of mouse IgG. Selection of an appropriate reference sequence for the other constant region of each IgG in this study is significant because no information on the DNA sequence has been established for $C_{H} 1, C_{H} 2$, and $C_{H} 3$ regions of these IgGs. Several different sequences have been reported for the constant region of the heavy chain of mouse IgGs that belong to the same subclass [18-26] but are derived from another mouse strain.

\section{$\operatorname{IgG1}$}

For the sequences of the constant region of the heavy chain, attention was paid to two sequences: sequence (a) reported by Honjo et al. [18] and sequence (b) reported by Adetugbo et al. [19]. These two sequences are highly homologous, but a small number of differences do exist. No description of the allotypes of the IgG1 studied was mentioned in these papers. We paid attention to both sequences because there are no proper criteria to justify selection of one amino acid sequence as reference. 
MALDI/TOF-MS peptide mapping. Figure 2 shows MALDI/TOF mass spectra of the peptides derived from the lysyl-endopeptidase digestion of RCM IgG1. To observe as many molecular ion peaks as possible, two kinds of matrices - DHBA and a mixture of sinapinic acid: HABA (20:1)-were tested for the analysis. Addition of 5\% HABA to sinapinic acid increases the number of the peptides that can be detected in a single MALDI spectrum, compared to the matrix of sinapinic acid alone, with respect to detection of components of higher molecular weight. As Figure $2 a$ and $b$ shows, a considerable number of protonated molecular ions of the peptides were observed. The results are summarized in Table 1. The specificity of the enzymes used for the digestion of RCM IgG1 was taken into account to interpret the MALDI/TOF mass spectra. For example, an intense peak at $m / z 2810.9$ in Figure $2 b$, which also was observed in Figure $2 a$ at $m / z$ 2808.2, was assigned to the protonated molecular ion of $20 \mathrm{H}-43 \mathrm{H}$. (The numbering system used in the present article for the constant region is based on human myeloma protein Eu for the heavy chain [27] and mouse myeloma protein MOPC21 for the light chain [20]. Amino acid residues in the heavy and light chains are identified by $\mathrm{H}$ and L, respectively, e.g., Asn $297 \mathrm{H}$ and Trp35L, or $297 \mathrm{H}$ and 35L.)

The structure of the $\mathrm{N}$-linked oligosaccharides at Asn297H is known to be heterogeneous. In the case of IgG1 used in the present study, the structures of the $\mathrm{N}$-linked oligosaccharides were determined previously, as shown in Figure 2 [16]. Three peaks were observed at $m / z$ 7269.5, 7427.4, and 7588.9 in the MALDI/TOF mass spectrum of the lysyl-endopeptidase digest (Figure 2b), and these peaks are the molecular ions of glycopeptide $269 \mathrm{H}-317 \mathrm{H}$. Similarly, other triplet peaks also were observed at $m / z$ 8371.8, 8533.1, and 8689.0 , which are the molecular ions of glycopeptide $259 \mathrm{H}-317 \mathrm{H}$. The observed mass values were consistent with the reported structure of the oligosaccharides shown in Figure 2.

It was not possible to assign an intense peak observed in Figure $2 b$ at $m / z 6559.7$ to any part of either sequence (a) or (b). It was decided that the sequence of this peptide should be determined.

MALDI/TOF-MS peptide mapping of the lysylendopeptidase digest of RCM IgG1 indicated that about $70 \%$ of the amino acid sequences of IgG1 are identical to the reference sequences and that sequence (a) reported by Honjo et al. [18] is more appropriate than sequence (b) as a reference for the constant region of the heavy chain. Hence sequence (a) was used as a reference sequence for IgG1. Some parts of the sequences could not be confirmed by the MALDI/TOFMS peptide mapping, possibly because too many peptides were produced by the lysyl-endopeptidase digestion of RCM IgG1. It is possible also that amino acid substitutions exist in the sequence of IgG1 that originates from haplotype-j mice. The existence of amino acid substitutions at Asp399H, Asp401H, and Ile406H in IgG1 that were found in a previous NMR study [28] has been confirmed by this peptide mapping.

To establish the complete amino acid sequences of IgG1, digestion with V8 protease also was utilized for MALDI/TOF-MS peptide mapping. Table 2 summarizes the observed mass values in the MALDI/TOF mass spectra of the peptides produced by the digestion of RCM IgG1 with V8 protease. All of the sequences of the light chain of IgG1 that originate from haplotype-j mice were identified as identical to reference sequence (a), but only $87 \%$ of the sequence of the heavy chain proved to be identical to the reference sequence, even though two kinds of enzymes were used for the peptide mapping. At this stage, the sequences of small peptides at the $\mathrm{N}$ - and the C-terminus of the heavy chain and the sequence of Gly $148 \mathrm{H}$-Lys $210 \mathrm{H}$ could not be confirmed.

LC/ESI-MS peptide mapping. Capillary LC/ESI-MS analysis was applied to the lysyl-endopeptidase digest of RCM IgG1 to complete the assignment of the observed mass values to the peptides. Figure 3 shows the UV chromatogram of capillary HPLC of the lysylendopeptidase digest. Protonated molecular masses calculated by deconvolution of the observed ions in LC/ ESI-MS analysis of the lysyl-endopeptidase digest of RCM IgG1 also are summarized in Table 1. The investigation of the sequences of the $\mathrm{C}$ - and $\mathrm{N}$-terminal parts and of the other unidentified regions in IgG1 will be discussed in the following text.

By LC/ESI-MS analyses, the C-terminal peptide of RCM IgG1 that was not observed in MALDI/TOF-MS spectra could be identified. Both of the C-terminal peptides Ser440H-Gly446H and Ser440H-Lys446AH were found in peaks 8 and 6 , respectively, and it was proved that the C-terminal Lys residue is missing in some proportion of IgG1 in this study. The N-terminal part of the heavy chain (Glu1H-Glu6H) and the region of Gly148H-Glu196H were not confirmed by LC/ESIMS analysis of the lysyl-endopeptidase digest of RCM IgG1. Consequently, the digest of V8 protease also was applied to capillary LC/ESI-MS analysis. In the LC/ESI mass spectrum, molecular peaks of the $\mathrm{N}$-terminal peptide Glu1H-Glu6H were observed at $\mathrm{m} / z 373.8$ $(2+)$ and $746.2(1+)$, but no molecular ion of the peptide around the region of Gly148H-Glu196H could be observed.

An ion at $m / z 1640.7$ was observed in peak 62 by capillary LC/ESI-MS analysis (Figure 3 ). This ion was estimated to be a $4+$ peptide ion and its molecular weight was calculated by deconvolution to be 6558.8 . It is possible that the $4+$ ion at $m / z 1640.7$ in Figure 3 and the ion at $m / z 6559.7$ in Figure $2 \mathrm{~b}$ were derived from the same peptide. We tentatively assigned this peptide to Gly148H-Lys $210 \mathrm{H}$, because this was the only peptide whose molecular weight had not been confirmed at this stage. The molecular weight of the peptide $148 \mathrm{H}-210 \mathrm{H}$ was calculated to be 6525.2 (average mass) from the reference sequence (a) [18] and the 
Table 1. Observed mass values in MALDI/TOF-MS and capillary LC/ESI-MS of the lysyl-endopoptidase digest of RCM IgG1 with the attribution of the mass numbers to the previously reported sequence (a) $[16-18,28]$

\begin{tabular}{|c|c|c|c|c|c|c|c|c|c|c|c|}
\hline \multirow[b]{2}{*}{$H$ or $L^{B}$} & \multicolumn{2}{|c|}{ position } & \multirow{2}{*}{$\begin{array}{c}(M+H)^{+} \\
\text {MALDI } \\
\text { obs. }^{c}\end{array}$} & \multirow[b]{2}{*}{$\Delta m^{\mathrm{d}}$} & \multirow{2}{*}{$\begin{array}{c}\text { LC-MS } \\
\text { peak } \\
\text { no. }\end{array}$} & \multirow{2}{*}{$\begin{array}{c}\mathrm{CM}_{+} \mathrm{HJ}^{+} \\
\mathrm{LC} / \mathrm{MS} \\
\text { obs.' }^{\prime}\end{array}$} & \multirow{2}{*}{$\begin{array}{c}\text { expect. } \\
\text { average }^{\theta}\end{array}$} & \multirow[b]{2}{*}{$\Delta m^{d}$} & \multirow{2}{*}{$\begin{array}{l}\text { expected } \\
\text { mono- } \\
\text { isotopich }^{h}\end{array}$} & \multirow[b]{2}{*}{$\Delta m^{i}$} & \multirow[b]{2}{*}{ Comment } \\
\hline & From $^{b}$ & $T_{0^{b}}$ & & & & & & & & & \\
\hline & 1 & 39 & 4921.4 & 0.9 & 48 & 4919.8 & 4920.5 & -0.7 & 4917.4 & 2.4 & \\
\hline L & 1 & 45 & n.d. ${ }^{j}$ & & 47 & 5513.0 & 5414.5 & -0.7 & 5511.7 & 2.8 & \\
\hline L & 1 & 74 & n.d. & & 51 & 8642.8 & 8647.6 & -1.5 & 8641.4 & 6.2 & \\
\hline L & 40 & 45 & n.d. & 1 & 61 & 3.1 & 613.7 & -0.6 & 613.3 & -0.2 & \\
\hline L & 46 & 50 & 648.8 & -1.1 & 28 & 649.2 & 649.9 & -0.6 & 649.4 & -0.2 & \\
\hline L & 51 & 74 & 2519.9 & 0.2 & 32 & 2519.2 & 2519.7 & -0.5 & 2518.2 & 1.0 & \\
\hline L & 51 & 103 & n.d. & & 53 & 5722.0 & 5723.3 & -1.3 & 5719.7 & 2.3 & \\
\hline L & 75 & 103 & 3222.6 & 0.0 & 46 & 3221.6 & 3222.6 & -1.0 & 3220.5 & 1.1 & \\
\hline L & 75 & 107 & 3705.6 & -0.6 & & n.d. & 3706.2 & & 3703.8 & & . \\
\hline L & 104 & 107 & n.d. & & 18 & 502.3 & 502.6 & -0.3 & 502.3 & 0.0 & \\
\hline$L$ & 108 & 142 & 3731.3 & 0.1 & 61 & 3729.4 & 3731.2 & -1.8 & 3728.8 & 0.6 & \\
\hline L & 143 & 147 & n.d. & & 11 & 588.3 & 588.7 & -0.4 & 588.3 & 0.0 & \\
\hline$L$ & 148 & 149 & n.d. & & & n.d. & 333.4 & & 333.2 & & \\
\hline L & 150 & 169 & 2251.5 & 1.2 & 29 & 2250.0 & 2250.4 & -0.3 & 2249.0 & 1.0 & \\
\hline L & 170 & 183 & n.d. & & 30 & 1535.3 & 1535.7 & -0.4 & 1534.7 & 0.6 & \\
\hline L & 170 & 207 & n.d. & & 33 & 4371.5 & 4372.8 & -1.3 & 4370.0 & 1.5 & \\
\hline L & 184 & 199 & 2042.5 & 0.4 & 12 & 2041.6 & 2042.1 & -0.5 & 2040.8 & 0.8 & \\
\hline L & 184 & 199 & 2063.8 & -0.3 & 12 & n.d. & 2064.1 & & 2064.8 & & $-\mathrm{Na}^{\mathrm{k}}$ \\
\hline L & 200 & 207 & 834.0 & 1.0 & 13 & 832.3 & 833.0 & -0.7 & 832.5 & -0.2 & \\
\hline L & 208 & 214 & 927.3 & -0.7 & 10 & 927.2 & 928.0 & -0.8 & 927.4 & -0.2 & \\
\hline L & 208 & 214 & 949.5 & -0.5 & & n.d. & 950.0 & & 949.4 & & $-\mathrm{Na}$ \\
\hline H & 1 & 3 & n.d. & & & n.d. & 375.5 & & 375.2 & & \\
\hline H & 4 & 19 & n.d. & & 21 & 1545.1 & 1546.7 & -1.6 & 1545.8 & -0.7 & \\
\hline $\mathrm{H}$ & 20 & 43 & 2808.2 & -0.9 & 54 & 2807.8 & 2809.1 & -1.3 & 2807.2 & 0.6 & \\
\hline H & 20 & 43 & 2830.3 & -0.8 & 54 & n.d. & 2831.1 & & 2829.2 & & $+\mathrm{Na}$ \\
\hline$H$ & 44 & $52 \mathrm{~B}$ & 1315.2 & -0.3 & 36 & 1315.5 & 1315.5 & 0.0 & 1314.7 & 0.8 & \\
\hline$H$ & 44 & $52 B$ & 1337.2 & -0.3 & & n.d. & 1337.5 & & 1336.7 & & $+\mathrm{Na}$ \\
\hline $\mathrm{H}$ & $52 \mathrm{C}$ & 64 & 1470.3 & 1.7 & 17 & 1467.5 & 1468.6 & -1.1 & 1467.7 & -0.2 & \\
\hline$H$ & $52 \mathrm{C}$ & 75 & n.d. & & 31 & 2731.0 & 2731.9 & -0.9 & 2730.3 & 0.7 & \\
\hline$H$ & 65 & 75 & 1281.7 & -0.7 & 19 & 1281.9 & 1282.4 & -0.5 & 1281.7 & 0.3 & \\
\hline$H$ & 65 & 119 & n.d. & & 57 & 6647.8 & 6650.5 & -2.7 & 6646.3 & 1.5 & \\
\hline $\mathrm{H}$ & 76 & 119 & 5385.7 & -1.4 & 59 & 5386.6 & 5387.1 & -0.5 & 5383.6 & 3.0 & \\
\hline $\mathrm{H}$ & 120 & 147 & n.d. & & 44 & 2862.4 & 2863.3 & -0.9 & 2861.4 & 1.0 & \\
\hline$H$ & 148 & 210 & n.d. & & & n.d. & 6526.2 & & 6522.2 & & \\
\hline$H$ & 211 & 214 & n.d. & & 7 & 489.4 & 489.6 & -0.2 & 489.3 & 0.1 & \\
\hline$H$ & 215 & 225 & n.d. & & 39 & 1107.9 & 1107.3 & 0.6 & 1106.5 & 1.4 & \\
\hline H & 215 & 246 & 3169.9 & 1.2 & 48 & 3166.9 & 3168.7 & -1.8 & 3166.5 & 0.4 & \\
\hline H & 215 & 246 & 3190.5 & -0.2 & & n.d. & 3190.7 & & 3198.5 & & \\
\hline H & 215 & 317 & n.d. & & 64 & 12823.4 & 12827.3 & -3.9 & 12819.1 & 4.3 & Sugar-linked' \\
\hline H & 215 & 317 & n.d. & & 64 & 12995.0 & 12989.5 & 5.5 & 12981.1 & 13.9 & Sugar-linked \\
\hline H & 215 & 317 & n.d. & & 64 & 13115.4 & 13151.6 & -36.2 & 13143.2 & -27.8 & Sugar-linked \\
\hline$H$ & 247 & 248 & n.d. & & & n.d. & 244.3 & & 244.2 & & \\
\hline H & 249 & 258 & n.d. & & 37 & 1100.4 & 1101.3 & -0.9 & 1100.7 & -0.3 & \\
\hline$H$ & 259 & 268 & 1122.0 & -0.3 & 29 & 1120.8 & 1121.3 & -0.5 & 1120.6 & 0.2 & \\
\hline $\mathrm{H}$ & 259 & 317 & 8371.8 & 1.8 & 58 & 8366.8 & 8370.0 & -3.2 & 8364.8 & 2.0 & Sugar-linked \\
\hline $\mathrm{H}$ & 259 & 317 & 8533.1 & 0.9 & 58 & 8528.2 & 8532.2 & -3.9 & 8526.9 & 1.3 & Sugar-linked \\
\hline $\mathrm{H}$ & 259 & 317 & 8689.0 & -5.3 & 58 & 8990.8 & 8694.3 & -3.5 & 8688.9 & 1.9 & Sugar-linked \\
\hline $\mathrm{H}$ & 269 & 317 & 7269.5 & 1.8 & 56 & 7264.0 & 7267.7 & -3.7 & 7263.3 & 0.8 & Sugar-linked \\
\hline H & 269 & 317 & 7427.4 & 2.4 & 56 & 7425.0 & 7429.8 & -4.8 & 7425.3 & -0.3 & Sugar-linked \\
\hline H & 269 & 317 & 7588.9 & -3.1 & 56 & 7592.5 & 7592.0 & 0.5 & 7587.4 & 5.1 & Sugar-linked \\
\hline
\end{tabular}


Table 1. (Continued).

\begin{tabular}{|c|c|c|c|c|c|c|c|c|c|c|c|}
\hline \multirow[b]{2}{*}{$\mathrm{H}$ or $L^{8}$} & \multicolumn{2}{|c|}{ position } & \multirow{2}{*}{$\begin{array}{c}(\mathrm{M}+\mathrm{H})^{+} \\
\text {MALDI } \\
\text { obs. }^{c}\end{array}$} & \multirow[b]{2}{*}{$\Delta m^{\mathrm{d}}$} & \multirow{2}{*}{$\begin{array}{c}\text { LC-MS } \\
\text { peak } \\
\text { no. }\end{array}$} & \multirow{2}{*}{$\begin{array}{c}{\left[\mathrm{M}_{+} \mathrm{H}\right]^{+}} \\
\mathrm{LC} / \mathrm{MS} \\
\text { obs. }^{\prime}\end{array}$} & \multirow{2}{*}{$\begin{array}{c}\text { expect. } \\
\text { average }^{g}\end{array}$} & \multirow[b]{2}{*}{$\Delta m^{\mathrm{d}}$} & \multirow{2}{*}{$\begin{array}{c}\text { expected } \\
\text { monoisotopic }\end{array}$} & \multirow[b]{2}{*}{$\Delta m^{i}$} & \multirow[b]{2}{*}{ Comment } \\
\hline & From $^{b}$ & $\mathrm{To}^{\mathrm{b}}$ & & & & & & & & & \\
\hline $\mathrm{H}$ & 318 & 320 & n.d. & & 6 & 423.3 & 423.5 & -0.2 & 423.2 & 0.1 & \\
\hline H & 321 & 334 & 1561.5 & -0.3 & 27 & 1560.2 & 1561.8 & -1.6 & 1560.8 & -0.6 & \\
\hline H & 321 & 334 & 1583.9 & 0.1 & & n.d. & 1583.8 & & 1562.8 & & $+\mathrm{Na}$ \\
\hline H & 335 & 338 & n.d. & & 2 & 448.2 & 448.5 & -0.3 & 448.3 & -0.1 & \\
\hline$H$ & 339 & 344 & n.d. & & $\cdot$ & n.d. & 686.8 & & 686.4 & & \\
\hline H & 341 & 344 & 457.4 & -0.2 & & n.d. & 457.6 & & 457.3 & & \\
\hline H & 345 & 355 & n.d. & & 23 & 1210.4 & 1211.5 & -1.0 & 1210.7 & -0.3 & \\
\hline$H$ & 356 & 360 & n.d. & & 3 & 606.3 & 606.7 & -0.4 & 606.3 & 0.0 & \\
\hline H & 356 & 362 & n.d. & & 20 & 850.4 & 850.0 & 0.4 & 849.4 & 1.0 & \\
\hline$H$ & 363 & 392 & n.d. & & 66 & 3621.1 & 3622.0 & -0.9 & 3619.6 & 1.5 & \\
\hline$H$ & 393 & 409 & n.d. & & 34 & 1979.8 & 1981.2 & -1.4 & 1979.9 & -0.1 & \\
\hline $\mathrm{H}$ & 393 & 439 & n.d. & & 45 & 5452.2 & 5453.0 & -0.8 & 5449.5 & 2.7 & \\
\hline $\mathrm{H}$ & 410 & 414 & n.d. & & 9 & 601.3 & 601.7 & -0.4 & 601.4 & -0.1 & \\
\hline H & 415 & 439 & 2907.4 & -0.7 & 35 & 2906.8 & 2908.1 & -1.3 & 2906.3 & 0.5 & \\
\hline$H$ & 440 & 446 & n.d. & & 8 & 684.4 & 684.7 & -0.3 & 684.4 & 0.0 & \\
\hline $\mathrm{H}$ & 440 & 446B & n.d. & & 6 & 812.3 & 812.9 & -0.6 & 812.4 & -0.1 & \\
\hline- & & & 6559.7 & & 62 & 6559.8 & & & & & $148 \mathrm{H}-21 \mathrm{OH}^{\mathrm{n}}$ \\
\hline
\end{tabular}

${ }^{a}$ Heavy chain (H) or light chain (L).

The position of the amino acid residue.

cobserved mass value in MALDI/TOF-MS

Mass difference between the observed and expected average mass values.

Peak number in Figure 3.

'Observed mass value in LC/ESI-MS calculated by deconvolution.

Expected average mass value.

"Expected monoisotopic mass value.

Mass difference between the observed and expected monoisotopic mass values.

Not detected.

kSodium adduct.

'Sugar-linked peptide.

"Estimated attribution.

mass difference between the observed and the theoretical values based on the reference sequence was about 34 u. Accordingly, it was concluded that substitution of amino acid(s) exists in this region.

Characterization of the region of $148 \mathrm{H}-210 \mathrm{H}$. The peptide Gly148H-Lys $210 \mathrm{H}$ was isolated by RP-HPLC, and digested with chymotrypsin. The digest was subjected to LC/ESI-MS analysis. Figure 4 shows a UV chromatogram of chymotryptic digest of the peptide Gly148H-Lys $210 \mathrm{H}$. The protonated molecular masses of the peptides Gly148H-Trp158H and Asn159HTyr $180 \mathrm{H}$, observed in ESI-MS, were determined by deconvolution to be 1295.7 and 2180.8 , respectively. These mass values are in good agreement with the expected mass values based on the reference sequences $[18,19]$. It is possible that the peak at $45.5 \mathrm{~min}$ in Figure 4 is due to the peptide Thr $181 \mathrm{H}$-Lys $210 \mathrm{H}$, but the molecular mass obtained for this peptide by deconvolution is $33.6 \mathrm{u}$ greater than the calculated value based on both of the reference sequences $[18,19]$. This mass difference can be brought about by a single amino acid substitution, such as Phe for Leu, Met for Pro, or Tyr for Glu. To determine the sequence of this peptide, it was subjected to amino acid sequence anal- ysis after isolation by RP-HPLC. Thu and Trp were found instead of Pro193H and Arg194H, respectively. It is of interest that the triplet codon for the found amino acid residues and those in the reference sequences are quite similar. The triplet codon for $\mathrm{Thr}$ is $A C X(X$ is $U, C, A$, or $G)$, whereas that for Pro is CCX. The difference between these two codons is only the first letter in the triplet. The difference in the triplet codon for Trp and Arg is similar. The theoretical mass value of the protonated molecular ion of this peptide can be calculated to be 3119.5 (average mass), which is in good agreement with the observed average mass value in LC/ESI-MS. The revised sequence of this peptide was confirmed by $\mathrm{FAB}$ mass spectrometry analysis, where the detection of monoisotopic protonated molecular ions was via a sector-type instrument. Thus the primary structure of IgG1 was determined as shown in Figure 5.

\section{IgG2a, IgG2a(s), and IgG2b}

Mass spectrometric characterizations of the amino acid sequences for IgG2a, IgG2a(s), and IgG2b were carried out also. Three sequences have been reported for the constant region of the heavy chain of IgG2a that car- 
Table 2. Observed mass values in MALDI/TOF-MS of the Staphylococcus aureus V8 protease digest of RCM IgG1, with the attribution of the mass numbers of the previously reported sequence (a) $[16-18,28]$.

\begin{tabular}{|c|c|c|c|c|c|c|c|}
\hline \multirow[b]{2}{*}{$H$ or $L^{\circ}$} & \multicolumn{2}{|c|}{ Position } & \multirow{2}{*}{$\begin{array}{c}{[\mathrm{M}+\mathrm{H}]^{+}} \\
\text {obs. }^{c}\end{array}$} & \multirow{2}{*}{$\begin{array}{l}{[\mathrm{M}+\mathrm{H}]^{+}} \\
\text {expect. }^{d}\end{array}$} & \multirow[b]{2}{*}{$\Delta m^{e}$} & \multirow[b]{2}{*}{ Comment } & \multirow[b]{2}{*}{$R$ or $L^{f}$} \\
\hline & Fromb & $\mathrm{To}^{\mathrm{b}}$ & & & & & \\
\hline $\mathrm{L}$ & 1 & 79 & $9,232.8$ & $9,231.4$ & 1.4 & & $\mathrm{~L}$ \\
\hline L & 1 & 105 & $12,104.2$ & $12,092.6$ & 11.6 & & $\mathbf{L}$ \\
\hline $\mathrm{L}$ & 106 & 123 & $1,886.5$ & $1,887.4$ & -0.9 & & $\mathbf{R}$ \\
\hline$L$ & 124 & 154 & $3,489.0$ & $3,489.9$ & -0.9 & & R, L \\
\hline L & 124 & 185 & 6.980 .7 & $6,980.7$ & 0.0 & & L \\
\hline L & 155 & 185 & $3,509.5$ & $3,509.8$ & -0.3 & & $\mathbf{R}$ \\
\hline$L$ & 186 & 195 & $1,359.3$ & 1.360 .4 & -1.1 & & $R$ \\
\hline L & 188 & 195 & $1,067.3$ & $1,068.1$ & -0.8 & & 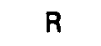 \\
\hline $\mathbf{L}$ & 196 & 214 & $2,178.9$ & $2,179.4$ & -0.5 & & $\mathbf{R}$ \\
\hline H & 1 & 6 & n.d. ${ }^{9}$ & 746.8 & & & \\
\hline H & 7 & 42 & $3,837.2$ & $3,837.2$ & 0.0 & & $R, L$ \\
\hline $\mathrm{H}$ & 43 & 50 & 931.8 & 932.1 & -0.3 & & $\mathrm{R}$ \\
\hline H & 51 & 61 & $1,665.2$ & $1,665.8$ & -0.6 & & $\mathbf{R}$ \\
\hline$H$ & 51 & 61 & $1,689.2$ & $1,687.8$ & 1.4 & $-\mathrm{Na}^{h}$ & $\mathbf{R}$ \\
\hline H & 62 & 85 & n.d. & $3,228.7$ & & & \\
\hline $\mathrm{H}$ & 86 & 152 & n.d. & $7,122.1$ & & & \\
\hline $\mathrm{H}$ & 153 & 196 & n.d. & $4,476.9$ & & & \\
\hline $\mathrm{H}$ & $196 \mathrm{~A}$ & 236 & n.d. & $3,992.6$ & & & \\
\hline $\mathrm{H}$ & 237 & 272 & 3987.7 & 3.987 .7 & 0.0 & & $R, L$ \\
\hline$H$ & 237 & 272 & $4,009.1$ & $4,010.7$ & -1.6 & $+\mathrm{Na}$ & $\mathbf{R}$ \\
\hline $\mathrm{H}$ & 237 & 283 & $5,338.2$ & $5,340.2$ & -2.0 & & $\mathrm{~L}$ \\
\hline H & 273 & 293 & $2,519.7$ & $2,519.7$ & 0.0 & & $\mathbf{R}$ \\
\hline H & 284 & 294 & $1,295.5$ & $1,296.4$ & -0.9 & & $\mathbf{R}$ \\
\hline $\mathrm{H}$ & 284 & 294 & $1,317.5$ & 1.318 .4 & -0.9 & $+\mathrm{Na}$ & $\mathbf{R}$ \\
\hline H & 295 & 305 & $2,747.7$ & $2,747.8$ & -0.1 & Sugar-linkedi & R \\
\hline $\mathrm{H}$ & 295 & 305 & 2.763 .8 & $2,763.8$ & 0.0 & Sugar-Linked & $\mathbf{R}$ \\
\hline $\mathrm{H}$ & 295 & 305 & $2,908.8$ & $2,909.9$ & -1.1 & Sugar-Linked & $\mathbf{R}$ \\
\hline H & 295 & 305 & $3,070.9$ & $3,072.0$ & -1.1 & Sugar-Linked & $\mathbf{R}$ \\
\hline H & 306 & 318 & $1,582.3$ & $1,581.8$ & 0.5 & & $\mathbf{R}$ \\
\hline $\mathrm{H}$ & 306 & 318 & $1,603.9$ & $1,603.8$ & 0.1 & $-\mathrm{Na}$ & $\mathbf{R}$ \\
\hline H & 319 & 333 & $1,708.6$ & $1,709.0$ & -0.4 & & $\mathrm{R}$ \\
\hline H & 319 & 333 & 1.730 .8 & $1,731.0$ & -0.2 & $+\mathrm{Na}$ & $\mathbf{R}$ \\
\hline H & 334 & 356 & $2,565.4$ & $2,566.1$ & -0.7 & & $R$ \\
\hline$H$ & 334 & 356 & $2,588.4$ & $2,588.1$ & 0.3 & $+\mathrm{Na}$ & $\mathbf{R}$ \\
\hline H & 357 & 375 & $2,263.4$ & $2,263.4$ & 0.0 & j & $R, L$ \\
\hline H & 357 & 380 & $2,822.2$ & $2,820.1$ & 2.1 & & $R, L$ \\
\hline H & 381 & 389 & $1,116.6$ & $1,116.2$ & 0.4 & & $\mathbf{R}$ \\
\hline H & 390 & 418 & $3,486.5$ & $3,485.7$ & 0.8 & & R, L \\
\hline H & 419 & 430 & $1,336.7$ & $1,337.5$ & -0.8 & & $\mathbf{R}$ \\
\hline$H$ & 419 & 438 & $2,263.4$ & $2,263.6$ & -0.2 & $\mathbf{j}$ & $R, L$ \\
\hline $\mathrm{H}$ & 431 & 438 & 944.4 & 945.0 & -0.6 & & $\mathbf{R}$ \\
\hline H & 431 & 438 & 966.1 & 967.0 & -0.9 & $+\mathrm{Na}$ & $\mathbf{R}$ \\
\hline $\mathrm{H}$ & 439 & 446 & n.d. & 942.0 & & & \\
\hline $\mathrm{H}$ & 439 & $446 \mathrm{~A}$ & n.d. & $1,070.0$ & & & \\
\hline
\end{tabular}

'Heavy chain (H) or light chain (L).

bThe position of the amino acid residue.

'Observed mass value.

'Expected average mass value.

'Mass difference between the observed and expected values.

Analyzed mode; reflector (R) or linear (L).

Not detected.

${ }^{\mathrm{h}}$ Sodium adduct.

'Sugar-linked peptide.

'Mass value that can be assigned to two positions.

ries allotype-a [21-24]. In LC/ESI-MS of the lysylendopeptidase digest of RCM IgG2a, an unidentified peptide with a protonated molecular mass of 2839.0 was found in peak 26 (Figure 6). The corresponding peak at $\mathrm{m} / \mathrm{z} 2837.7$ also was found in MALDI/TOF-MS analysis. It was proposed that this mass value could correspond to the protonated molecular ion of the peptide Thr120H-Lys147H, because the expected mass for this peptide could not be observed either in MALDI/TOF-MS or LC/ESI-MS analyses of the lysylendopeptidase digest. After isolation of this peptide, it was subjected to sequence analysis. A Ser residue was 
1640.7
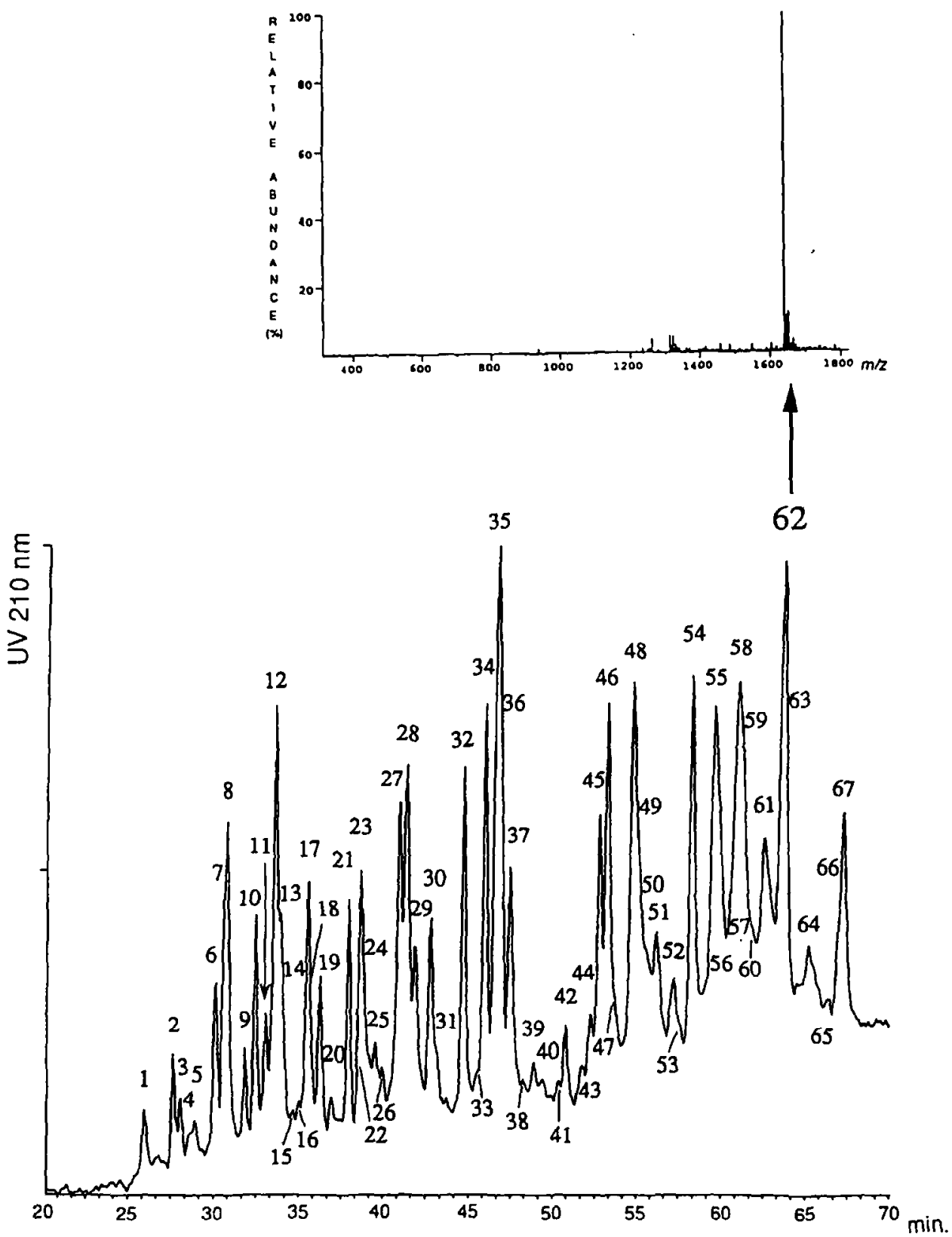

Figure 3. UV chromatogram obtained by capillary HPLC of the lysyl-endopeptidase digest of RCM IgC1 and an ESI mass spectrum of peak 62.

found instead of Thr136H. As in the case of IgG1, the difference in the triplet codon for Ser and Thr is only the first letter in the triplet. Therefore, such substitution could occur easily. The revised sequence of this peptide was confirmed by FAB mass spectrometry analysis, where the detection of monoisotopic protonated molecular ions was via a sector-type instrument.

The existence of $\mathrm{N}$-linked oligosaccharide at Asn297H in IgG2a also was confirmed in both MALDI/TOF-MS and LC/ESI-MS analyses of lysylendopeptidase and V8 protease digests. For example, glycopeptides $247 \mathrm{H}-317 \mathrm{H}$ and $249 \mathrm{H}-317 \mathrm{H}$ with sugar chain type $E$ and $F$ (and/or $G$ ) were observed in peak
46 in Figure 6. The existence of the C-terminal Lys residue in IgG2a was identified in both MALDI/TOFMS and LC/ESI-MS of the lysyl-endopeptidase digest of RCM IgG2a. The C-terminal peptide $440 \mathrm{H}-446 \mathrm{AH}$ was found in peak 5 in Figure 6 at $m / z 376.0(2+)$ and $751.1(1+)$. Only the C-terminal peptide that has Lys446AH at the C-terminal of the heavy chain was found in LC/ESI-MS analysis. The established sequence of IgG2a is indicated in Figure 5.

We observed that the C-terminal Lys of the heavy chain of IgG2a is missing when the IgG2a hybridoma cells are cultivated in mouse ascites (data not shown) and that the C-termini of the heavy chain are variable 


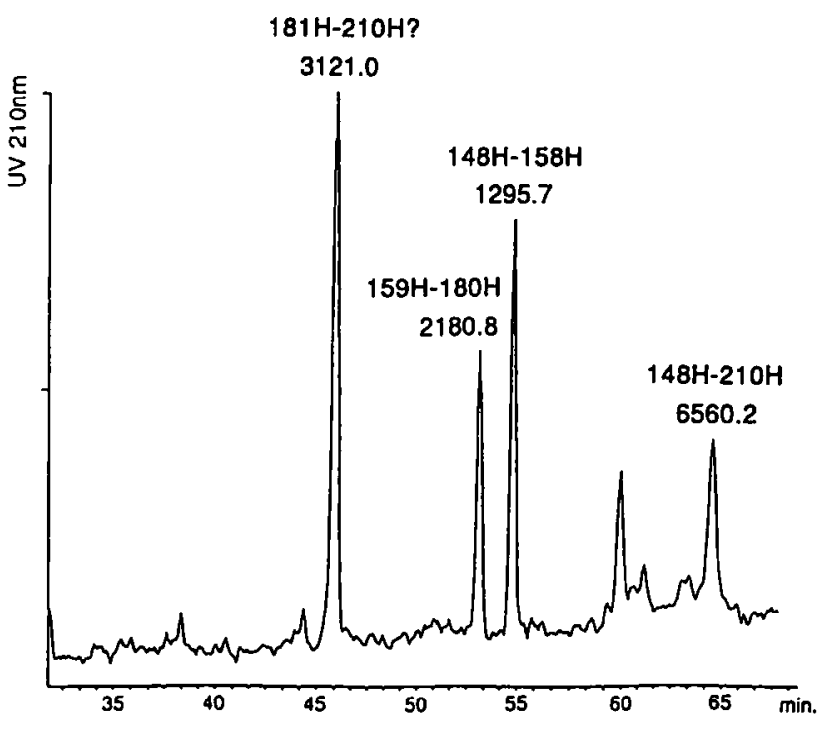

Figure 4. UV chromatogram obtained by capillary HPLC of the chymotryptic digest of peak 62 in Figure 3 . The number on each peak indicates the protonated molecular mass of the peptide contained in the peak.

in the mouse switch variant IgGs that is prepared in the same manner. In addition, the length of the amino acid sequences of IgG2a is different for those produced by the mouse cell culture (in vitro) and those produced in mouse ascites (in vivo). The variation of the $\mathrm{C}$ terminus of the heavy chain in the switch variant IgG2a and IgG2a(s) also was studied by NMR [29]; the results obtained here are consistent with those obtained by NMR.

The amino acid sequence of $\operatorname{IgG} 2 \mathrm{a}(\mathrm{s})$, in which the $\mathrm{C}_{\mathrm{H}} 1$ domain is deleted from IgG2a, was identical to the expected sequence $[21,22]$ except for the $C$ terminal Lys residue. The Lys residue at the C-terminus of the heavy chain of IgG2a(s) is absent in the majority of the population. A peptide Ser440H-Lys446AH with protonated molecular mass of 750.4 was found during LC/ESI-MS analysis of the lysyl-endopeptidase digest. As is the case of IgG2a, glycopeptides with an N-linked sugar chain were observed in LC/ESI-MS and MALDI/TOF-MS analyses. In LC/ESI-MS of the lysylendopeptidase digest of RCM IgG2a(s), molecular masses of 9700.8, 9296.4, and 9548.8 were observed in the deconvoluted spectra. These peaks correspond to glycopeptides $249 \mathrm{H}-317 \mathrm{H}$ with oligosaccharide type $\mathrm{F}$ (and/or G) and $247 \mathrm{H}-317 \mathrm{H}$ with oligosaccharide type $E$ and $F$ (and/or $G$ ). The established sequence of IgG2a(s) is summarized in Figure 5.

In the case of IgG2b, five sequences that carry allotype-a were reported for the constant region of the heavy chain $[20,22-26]$. In the IgG2b studied here, no substitution of the amino acid residue was found compared to a reference sequence [22, 25], which is identical to Figure 5, except for the absence of the C-terminal Lys residue. The existence of the $\mathrm{C}$-terminal Lys residue of the heavy chain in IgG2b could not be identified by MALDI/TOF-MS and capillary-LC/ESI-MS analyses.

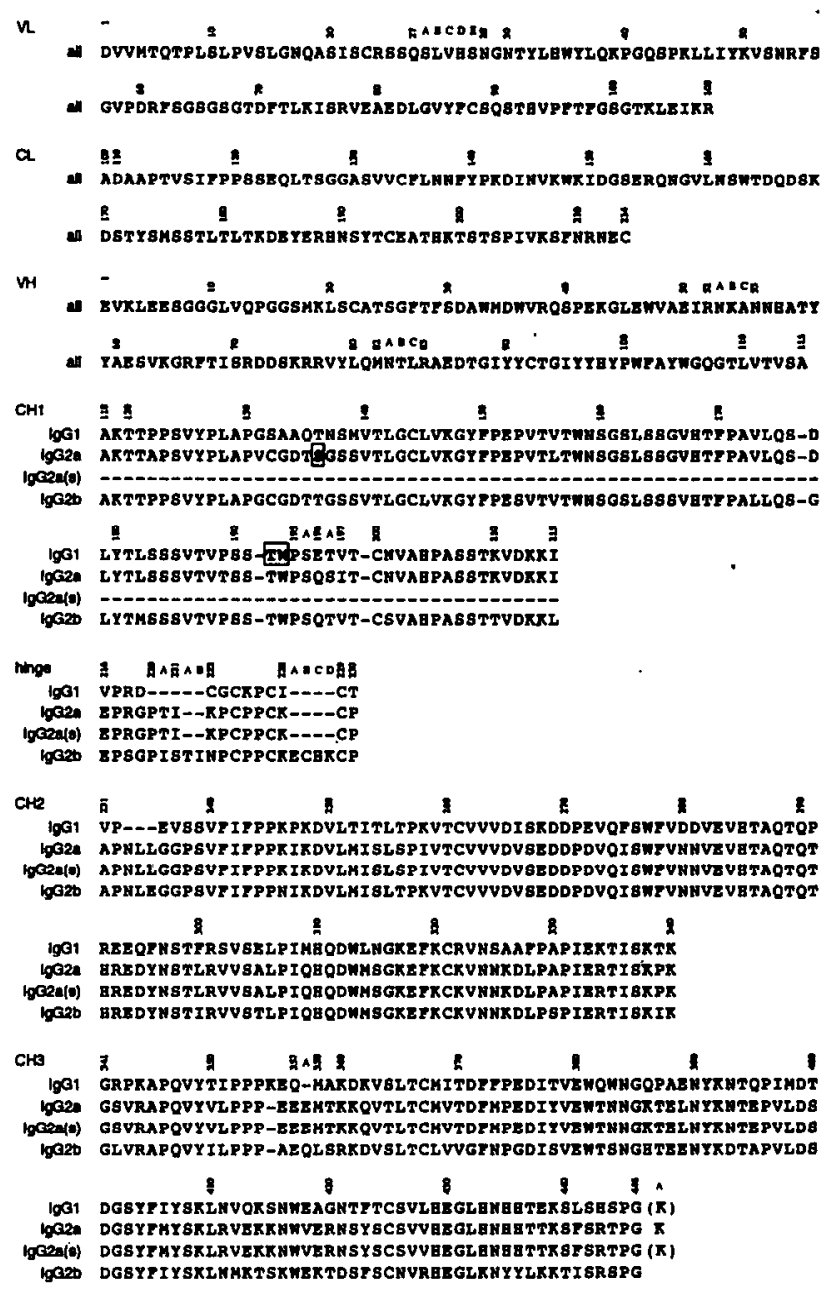

Figure 5. Amino acid sequences of switch variant immunoglobulins determined in this study.

All the C-terminal peptides observed in the analyses lacked Lys446AH. For example, the component of mass 716.6 in the deconvoluted spectrum in LC/ESI-MS corresponds to the peptide $440 \mathrm{H}-446 \mathrm{H}$, with no Lys residue. The existence of $\mathrm{N}$-linked oligosaccharides has been confirmed also in IgG2b. Type E, F (and/or G), and $\mathrm{H}$ sugar chains could be recognized in either LC/ESI-MS or MALDI/TOF-MS of the digests. For example, molecular weights of glycopeptides $259 \mathrm{H}$ $317 \mathrm{H}$ with sugar chain $\mathrm{E}, \mathrm{F}$ (and/or $\mathrm{G}$ ), and $\mathrm{H}$ were recognized in LC/ESI-MS of lysyl-endopeptidase digest of RCM IgG2b as 8256.0, 8418.0, and 8583.0, respectively, in the deconvoluted spectra.

In addition, the existence of O-linked oligosaccharides was verified by capillary LC/ESI-MS analysis of the lysyl-endopeptidase digest of RCM IgG2b in the present study. Previous reports claimed that about $40 \%$ of the populations of IgG2b had O-linked oligosaccharides at $\mathrm{Thr} 221 \mathrm{AH}$, whereas about $60 \%$ of the populations do not possess O-linked oligosaccharide [30]. The expected molecular weights of two $\mathrm{O}$ glycosylated peptides Lys $214 \mathrm{H}-\mathrm{Lys} 228 \mathrm{H}$ generated by lysyl-endopeptidase digestion are calculated to be 


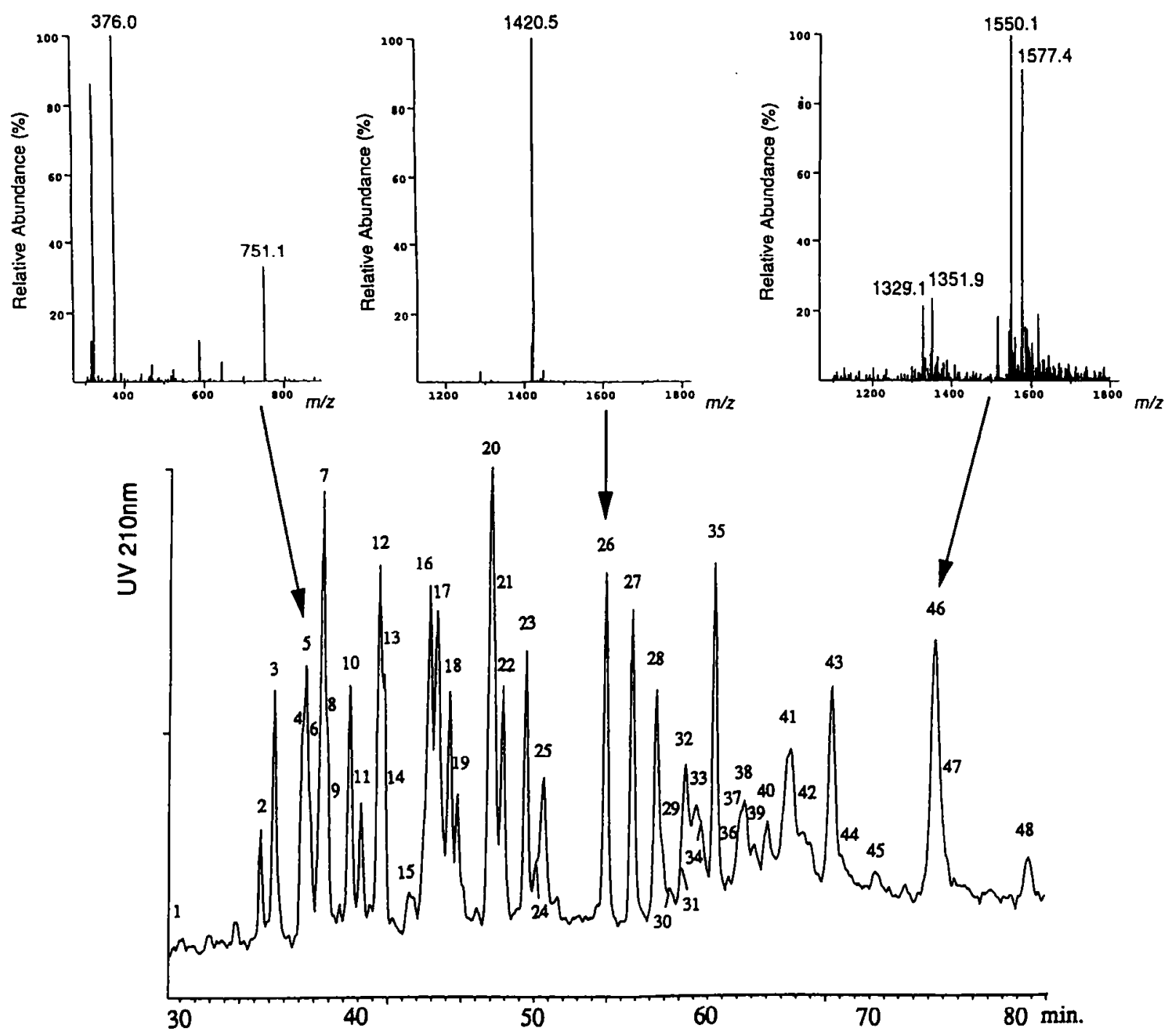

Figure 6. UV chromatogram obtained by capillary HPLC of the lysyl-endopeptidase digest of RCM IgG2a and ESI mass spectra of peak 5, 26, and 46.

2977.2 (average) and 2961.2 (average), whereas that of a nonglycosylated peptide can be calculated to be 1997.3 (average) (1996.0; monoisotopic). The relative content of these three peptides has been reported as 35 , 4 , and $60 \%$, respectively [30]. In LC/ESI-MS of the lysyl-endopeptidase digest of RCM IgG2b a nonglycosylated and an O-glycosylated peptide with molecular weights of 1996.2 and 2977.0 were observed. However, it was impossible to observe the other O-glycosylated peptide with molecular weight 2959.3, probably due to the very small amount of this component.

\section{Relationships between the Serological Properties and the Structures of Allotypic Markers}

Figure 7 shows a space-filling model of the $F_{a b}$ region of human IgG1 (PDB code 2IG2). The position $136 \mathrm{H}$, at which amino acid substitution exists in the case of $\mathrm{IgG2a}$, is indicated in red. Ser $136 \mathrm{H}$, which exists on the surface of the $\mathrm{C}_{\mathrm{H}} 1$ domain and is exposed to solvent, is facing the $C_{L}$ domain and is close to the hinge region. In the case of IgG1 produced by haplotype-j mice, substitutions of two amino acid residues, Thr193H and $\operatorname{Trp} 194 \mathrm{H}$, have been identified in this study. Amino acid residues at positions of $193 \mathrm{H}$ and $194 \mathrm{H}$ are indicated in green in Figure 7. Contrary to the case of IgG2a, these amino acids seem to be buried inside the structure.

It has been reported that allotypic markers for allotype-a and allotype-j of mouse IgG2a are located in the $\mathrm{F}_{\mathrm{ab}}$ fragment. However, amino acid residues that correspond to these allotypic markers have not been identified yet [14]. It is possible that $\operatorname{Ser} 136 \mathrm{H}$ in the $\mathrm{F}_{\mathrm{ab}}$ of IgG2a is related to the allotypic marker of allotype-j, although the structural difference between Ser and Thr residues is not so remarkable. If $\mathrm{Ser} 136 \mathrm{H}$ is related to the allotypic markers of allotype-j, it is reasonable that the amino acid residue at $136 \mathrm{H}$ is located on the surface of the molecule and allotype-a and -j of IgG2a can be distinguished only by a special guinea pig 


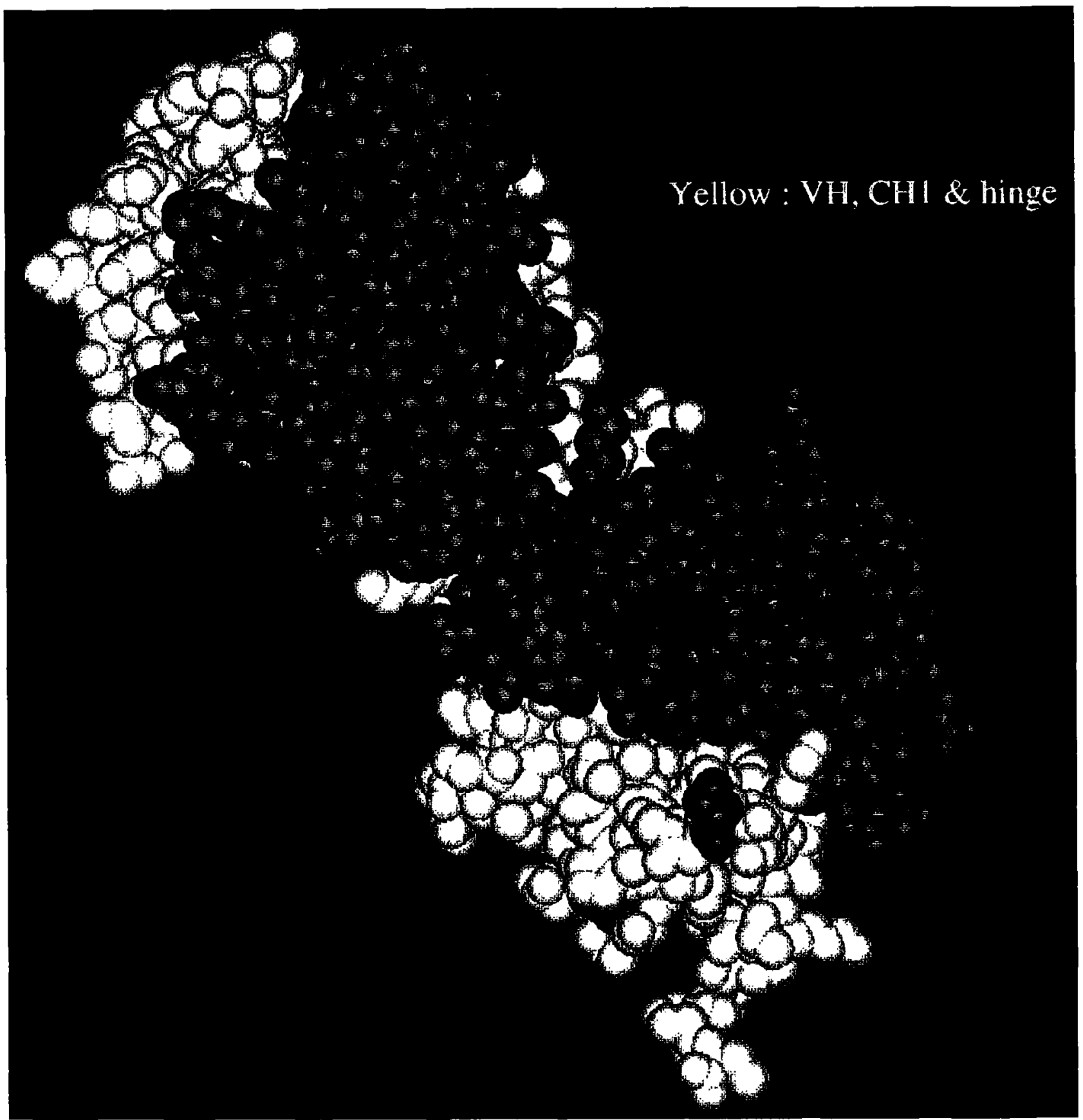

Figure 7. Space-filling model of the $\mathrm{F}_{\mathrm{ab}}$ region of human IgG1. The atomic coordinates of the immunoglobulin molecule were obtained from the Protein Data Bank (code 2IG2). The model was generated by using the program BIOCES. The $V_{H}$ and $C_{H} 1$ domains along with the hinge region are indicated in yellow. The $V_{L}$ and $C_{L}$ domains are indicated in blue. Ser137H in the heavy chain is indicated in red. Amino acid residues at $193 \mathrm{H}$ and $194 \mathrm{H}$ in the heavy chain are indicated in green.

antiserum. On the other hand, it is also quite possible that the structural differences in IgG1 cannot be distinguished by any antisera.

\section{Characteristics of Mass Spectrometric Techniques} in the Structural Investigation of Large Biological Molecules

Since its development, MALDI/TOF-MS often has been used for peptide mapping of proteins [1, 2, 31, 32]. Molecular weights of all the target proteins in these studies were less than 60,000 . Consideration of previous and current results allows us to conclude that MALDI/TOF-MS is effective for peptide mapping of proteins with a molecular weight of less than 60,000 . However, other supplementary analytical methods are required to complete the characterization of the structure of larger molecules. It is impossible to observe all the molecular ions of digested peptides in a single MALDI/TOF mass spectrum, even if several kinds of matrices are applied.

In the present work, LC/ESI-MS analysis was used 
for supplementary characterization of the sequences of IgGs. Assignments of molecular mass values to the peptides observed in capillary ESI mass spectra were achieved by comparison with the results detected in MALDI/TOF-MS. The results obtained by MALDI/ TOF-MS peptide mapping facilitated the assignment of the observed mass values in LC/ ESI-MS to the peptides, even if only one peak could be observed in the ESI mass spectrum and the deconvolution procedure was not successful. Accordingly, the assignment of the mass values observed in ESI-MS to the pepides was not difficult to perform.

In the present study, reduction and carboxymethylation were carried out before the structural investigation and the antibodies were transformed into four polypeptides: two RCM light chains with mass of 25 ku and two RCM heavy chains with mass of $51 \mathrm{ku}[41$ $\mathrm{ku}$ in the case of IgG2a(s)]. Accordingly, the molecular weights of the proteins dealt with in this study are actually less than $80 \mathrm{ku}$. The techniques and strategies used in the present work also can be applied to proteins with molecular weights of $80 \mathrm{ku}$ or more. In addition, although the number of peptides derived from the enzymatic digestion increases as the molecular weight of the protein increases, the molecular weight of the peptides can be determined by the same strategy used here.

\section{Conclusion}

We have confirmed that the amino acid sequences of the $V_{H}, V_{L}$, and $C_{L}$ regions are identical in all the switch variant IgGs. Several amino acid substitutions in the $C_{H} 1$ domain of IgG1 and IgG2a compared to the reference sequences were detected in this study. The existence of an allotypic marker on IgG2a was suggested in the $\mathrm{C}_{\mathrm{H}} 1$ domain.

The peptide mapping of a large protein such as IgG revealed that MALDI/TOF-MS is not as effective as it is in the case of a protein with molecular weight of less than 60,000 . This situation limits the application of MALDI/TOF-MS for peptide mapping: if too many peptides are generated by the digestion, it is difficult to detect all of them in a single MALDI/TOF mass spectrum. Capillary LC/ESI-MS was revealed to be more effective for the characterization of IgGs.

This study shows that amino acid sequences of proteins such as $\operatorname{IgG}$ can be investigated without information about the corresponding DNA sequence if it is possible to use appropriate reference sequences derived from other strains. In addition, the precise sequence analyses of $\mathrm{IgGs}$ make it possible to discuss the relationship between the structure and serological properties that is difficult to determine without mass spectrometry analyses.

\section{Acknowledgments}

We thank Professor L. A. Herzenberg, Stanford University, and Dr. V. T. Oi, Becton Dickinson Immunocy- tometry Systems, for generously providing the switch variant cell lines and sequence data of the $\mathrm{V}_{\mathrm{L}}$ region of IgG1.We are grateful to $M$. Kohmura and K. Shima, Ajinomoto Co., Inc., for operation of the amino acid sequencer. We also thank K. Ebisawa, Ajinomoto Co., Inc., for support in computational chemistry and for useful discussions.

\section{References}

1. Billeci, T. M.; Stults, J. T. Anal. Chem. 1993, 65, 1709-1716.

2. Karas, M.; Ehring, H.; Nordhoff, E.; Stahl, B.; Strupat, K.; Hillenkamp, F.; Grehl, M.; Krebs, B. Org. Mass Spectrom. 1993, 28, 1476-1481.

3. Feng, R.; Konishi, Y. Anal. Chem. 1992, 64, 2090-2095.

4. Feng, R.; Konishi, Y. Anal. Chem. 1993, 65, 645-649.

5. Ashton, D. S.; Beddell, C. R.; Cooper, D. J.; Craig, S. J.; Lines, A. C.; Oliver, R. W. A.; Smith, M. A. Anal. Chem. 1995, 67, 835-842.

6. Bourell, J. H.; Clauser, K. P.; Kelley, R.; Carter, P.; Stults, J. T. Anal. Chem. 1994, 66, 2088-2095.

7. Siegel, M. M.; Hollander, I. J.; Hamann, P. R.; James, J. P.; Hinman, L.; Smith, B. J.; Farnsworth, A. P. H.; Phipps, A.; King, D. J.; Karas, M.; Ingendoh, A.; Hillenkamp, F. Anal. Chem. 1991, 63, 2470-2481.

8. Lewis, D. A.; Guzzetta, A. W.; Hancock, W. S.; Costello, M. Anal. Chem. 1994, 66, 585-595.

9. Cano, L.; Swiderek, K. M.; Shively, J. E. In Techniques in Protein Chemistry VI; Crabb, J. W., Ed.; Academic Press: San Diego 1995; pp 21-30.

10. Roberts, G. D.; Johnson W. P.; Burman, S.; Anumula, K. R.; Carr, S. A. Anal. Chem. 1995, 67, 3613-3625.

11. van Loghem, E. Monogr.-Allergy 1986, 19, 40-51.

12. Dangl, J. L.; Parks, D. R.; Oi, V. T.; Herzenberg, L. A. Cytometry 1982, 2, 395-401.

13. Igarashi, T.; Sato, M.; Katsube, Y.; Takio, K.; Tanaka, T.; Nakanishi, M.; Arata, Y. Biochemistry 1990, 29, 5727-5733.

14. Spring, S. B.; Nisonoff, A. J. Immunol. 1974, 113, 470-478.

15. Kato, K.; Matsunaga, C.; Igarashi, T.; Kim, H.; Odaka, A.; Shimada, I.; Arata, Y. Biochemistry 1991, 30, 270-278.

16. Takahashi, N.; Ishii, I.; Ishihara, H.; Mori, M.; Tejima, S.; Jefferis, R.; Endo, S.; Arata, Y. Biochemistry 1987, 26, 1137-1144.

17. Dangl, J. L. Ph.D. Thesis, Standford University, 1986.

18. Honjo, T.; Obata, M.; Yamawaki-Kataoka, Y.; Kataoka, T.; Kawakami, T.; Takahashi, N.; Mano, Y. Cell 1979, 18, 559-568.

19. Adetugbo, K.; Poskus, E.; Svasti, J.; Milstein, C. Eur. J. Biochem. 1975, 56, 503-519.

20. Kabat, E. A.; Wu, T. T.; Perry, H. M.; Cottesman, K. S.; Foeller, C. Sequences of Proteins of Immunological Interest, 5th ed.; U.S. Department of Health and Human Services, National Institute of Health: Washington, DC, 1991.

21. Yamawaki-Kataoka, Y.; Miyata, T.; Honjo, T. Nucleic Acids Res. 1981, 9, 1365-1381.

22. Schreier, P. H.; Bothwell, A. L. M.; Mueller-Hill, B.; Baltimore, D. Proc. Natl. Acad. Sci. U.S. A. 1981, 78, 4495-4499.

23. Sikorav, J. L.; Auffray C.; Rougeon F. Nucleic Acids Res. 1980 , 8, 3143-3155.

24. Ollo, R.; Auffray C.; Morchamps, C.; Rougeon, F. Proc. Natl. Acad. Sci. U.S. A. 1981, 78, 2442-2446.

25. Yamawaki-Kataoka, Y.; Kataoka, T.; Takahashi, N.; Obata, M.; Honjo, T. Nature 1980, 283, 786-789.

26. Tucker, P. W.; Marcu, K. B.; Newell, N.; Richards, J.; Blattner, F. R. Science 1979, 206, 1303-1306.

27. Edelman, G. M.; Cunningham, B. A.; Gall, W. E.; Gottlieb, P. D.; Rutishauser, U.; Waxdal, M. J. Proc. Natl. Acad. Sci. USA 1969, 63, 78-85. 
28. Kim, H.; Kato, K.; Higuchi, A.; Nomura, N.; Noguchi, H.; Arata, Y. J. Immunol. Methods 1992, 153, 223-227.

29. Kim, H.; Matsunaga, C.; Yoshino, A.; Kato, K.; Arata, Y J. Mol. Biol. 1994, 236, 300-309.

30. Kim, H.; Yamaguchi, Y.; Masuda, K.; Matsunaga, $C_{\text {.; }}$ Yamamoto, K.; Irimura, T.; Takahashi, N.; Kato, K.; Arata, Y. J. Biol. Chem. 1994, 269, 12345-12350.
31. Huberty, M. C.; Vath, J. E.; Yu, W.; Martin, S. A. Anal. Chem. 1993, 65, 2791-2800.

32. Tsarbopoulos, A.; Karas, M.; Strupat, K.; Pramanik, B. N.; Nagabhushan, T. L.; Hillenkamp, F. Anal. Chem. 1994, 66, 2062-2070. 